\title{
A mediatização da Covid-19 em Portugal: os primeiros meses da pandemia nos jornais online
}

\section{Covid-19 media coverage in Portugal: the first months of the pandemic in online newspapers}

\author{
Emiliana Sofia Coelho Gomesa \\ a Centro de Estudos de Comunicação e Sociedade, Instituto de Ciências Sociais, Portugal
}

\section{Resumo}

Introdução: No final de 2019, deu-se início a uma crise de Saúde Pública com o surgimento do novo Coronavírus. Em poucos meses este vírus atingiu praticamente todos os países do mundo e, em Portugal, os primeiros casos foram registados em março de 2020. Objetivo: Perceber de que modo o Jornalismo online português mediatiza a COVID-19. Metodologia: Foram analisados os artigos noticiosos sobre COVID-19 publicados em quatro edições online: Jornal de Notícias, Público, Observador e Notícias ao Minuto. Resultados: Os 280 artigos apontam para um forte recurso a novas plataformas como as redes sociais e as versões móveis dos jornais, assim como se distingue a apresentação de números, a identificação de formas de prevenir a doença e a explicação sobre o processo de transmissão do vírus. Estas notícias são divulgadas maioritariamente, com foco nacional e com recurso a várias formas imagéticas. Evidencia-se, ainda, a assídua presenta de fontes de informação e o reduzido número de fontes por artigo. Conclusões: A crise gerada pela COVID-19 veio consolidar o uso de plataformas digitais que fomentaram um sistema mediático híbrido, em que coexistiram novos e antigos meios de comunicação, assim como trouxe novas formas de comunicação e novos desafios, equacionando-se as potencialidades do Jornalismo.

Palavras-chave: jornalismo em saúde; COVID-19; coronavírus; fontes de informação.

\begin{abstract}
Introduction: In the end of 2019 , a Public Health crisis began with the emergence of the new Coronavirus. In a few months this virus reached practically every country in the world and, in Portugal, the first cases were registered in March 2020. Objective: To understand how Portuguese online journalism mediates COVID-19. Methodology: we analysed the news articles on COVID-19 published in four online editions: Jornal de Notícias, Público, Observador and Notícias ao Minuto. Results: The 280 articles point to a strong use of new platforms such as social networks and mobile versions of newspapers, as well as distinguishing the presentation of figures, the identification of ways to prevent the disease and the explanation about the virus transmission process. These news are mostly disseminated with a national focus and with recourse to various imagetic forms. The assiduous presence of information sources and the reduced number of sources per article are also evident. Conclusions: The crisis generated by COVID-19 consolidated the use of digital platforms that fostered a hybrid media system, in which new and old media coexisted, as well as brought new forms of communication and new challenges, equating the potential of journalism.
\end{abstract}

Keywords: Health Journalism; COVID-19; coronavirus; sources of information. 


\section{Introdução}

O surgimento do novo Coronavírus (SARS-CoV-2), em dezembro de 2019, trouxe consigo uma nova realidade no panorama sanitário global: uma crise de Saúde Pública à escala mundial. Os primeiros casos de infetados com SARS-CoV-2 foram associados a um mercado na cidade chinesa Wuhan. Não obstante as entidades locais terem encerrado o espaço logo no início de janeiro de 2020, não foi possível travar a progressão do vírus, que acabou por desencadear uma pandemia, como definiu a Organização Mundial de Saúde.

COVID-19, a doença decorrente deste vírus, associase a sintomas semelhantes aos de uma gripe ou, em casos mais graves, aos de uma pneumonia. Num curto espaço de tempo, os doentes infetados com COVID-19 foram surgindo um pouco por todo o mundo (ValeroCedeño, Mina-Ortiz, Veliz-Castro, Merchán-Villafuerte \& Perozo-Mena, 2020). Em Portugal, os primeiros casos remontam ao início de março, tendo sido internados na cidade do Porto, na região Norte do país, os primeiros dois doentes (Direção-Geral da Saúde [DGS], 2020).

A rápida progressão deste vírus à escala mundial valeu a especial atenção dos media que, aceleradamente modificaram as suas agendas e se dedicaram praticamente em exclusivo à difusão de informação sobre o novo Coronavírus. A falta de certezas científicas sobre a COVID-19 e a necessidade de informar a população sobre a doença, transformou a informação jornalística num recurso essencial para a sociedade, destacando 0 papel dos meios de comunicação social na prevenção da doença e na promoção da saúde.

O estudo apresentado é desenvolvido no seio deste contexto pandémico e procura responder à pergunta de partida: "De que modo o Jornalismo online português mediatiza a COVID-19? Equaciona-se, portanto, o papel dos media com a identificação e o estudo de certas fontes de informação, através da análise e da caracterização dos artigos noticiosos publicados, nos primeiros meses da pandemia (entre abril e maio de 2019), em quatro jornais portugueses de expressão online: 0 Jornal de Notícias, 0 Público, o Observador e o Notícias ao Minuto.

Por se tratar de uma investigação desenvolvida no decorrer da pandemia que é alvo de estudo e que não tem, até ao momento, um fim à vista, o presente artigo não ambiciona chegar a conclusões definitivas, pois a situação está em permanente mutação. Aposta-se, pois, na apresentação de resultados preliminares de um trabalho a que se procurará dar continuidade no futuro.

\section{Um Jornalismo pela saúde}

A Saúde é um campo de estudo em crescente valorização. A sua relação com o Jornalismo não foge à regra, considerando a progressiva atenção jornalística de que tem sido alvo (Lopes \& Araújo, 2020; Cuéllar \& Martín-Pena, 2020). Para compreender as lógicas de recolha, produção e transmissão de conhecimento sobre Saúde, torna-se aliciante estudar o Jornalismo aplicado a esta área. Por ser um campo tão específico e de difícil compreensão para o cidadão-comum, os media adquirem o papel de fornecedores de informação sobre saúde (Gomes, 2019; Lopes \& Araújo, 2020).

Para Scott Ratzan (2002), a saúde é um elemento essencial da sociedade civil, aproximando-se da própria conceção de existência. Por seu turno, a Organização Mundial da Saúde (OMS) define o conceito como "0 estado do mais completo bem-estar físico, mental e social e não apenas a ausência de enfermidade" (OMS, 2006). Esta conceção evidencia a necessidade de avaliar o conceito de saúde num contexto social (Gomes, 2020; Naidoo \& Wills, 1998). Alinhado com o conceito de saúde da OMS está também o de Saúde Pública. Esta deverá ser definida como "a arte e a ciência da prevenção da doença, do prolongamento da vida e da promoção da saúde através dos esforços organizados da sociedade" (Acheson, 1988). Neste sentido, a Saúde Pública deve centrar-se, não somente na erradicação de doenças, como também no bem-estar das populações. Em consequência, os serviços de Saúde Pública devem incluir a prestação de serviços, tais como vacinação, orientação comportamental e de saúde.

De acordo com Francisco George, ex-diretor-geral da Saúde português, "as crises globais vividas nos últimos anos, colocaram a Saúde Pública na linha da frente das preocupações reais e emocionais dos Povos de todo 0 Mundo" (2011, p. 2).

À semelhança do que acontece no caso da Saúde, também a atividade jornalística varia em função de fatores tecnológicos, económicos e sociais. Esta contextualização do Jornalismo coloca em perspetiva o seu papel enquanto prática, produto e profissão (Pavlik, 2001; Spyridou, Matsiola, Veglis, Kalliris \& Dimoulas, 2013).

Como resposta a estas alterações, o Jornalismo procura reinventar-se, tornar-se mais atrativo e responder às carências da sua audiência (Gomes, 2020). Esta necessidade de resposta remete para uma intrínseca relação entre o Jornalismo e o interesse do público. Tratase de fortalecer a ideia de contrato social do Jornalismo. Como acontece em qualquer contrato, estabelece-se um vínculo entre, pelo menos, duas partes e, cada parte, 
tem direitos e responsabilidades (Marvin \& Meyer, 2005; SjØvaag, 2010). Assim, considerando a metáfora da relação contratual entre o Jornalismo e a sociedade, pode afirmar-se que o Jornalismo é responsável por prestar serviços à sociedade, enquanto esta tem o papel de fonte de informação das notícias a publicar (Eide, 2014; Raaum, 1986, 1999; SjØvaag, 2010; Strömbäck, 2005).

Desta forma, a razão de ser do Jornalismo está presente no exercício da cidadania, na construção da memória pública e na participação cívica (Martins, 2010). Partindo da relação direta entre Jornalismo e sociedade e do indiscutível interesse do público em assuntos de Saúde (Lopes \& Araújo, 2020), parece clara a necessidade de desenvolver estudos sobre o Jornalismo especializado em Saúde. Este procura, certamente, transmitir e explicar informações específicas, ultrapassando a sua função no debate democrático e a sua função crítica (Marcotte \& Sauvageau, 2006).

Partindo destes pressupostos, é fácil constatar que a sociedade leva em especial consideração as notícias sobre Saúde que recebe dos media e é com base nestas que toma decisões informadas (Gomes, 2020; Tamez, 2020). O Jornalismo em Saúde adquire, neste contexto, um papel de extrema relevância no que diz respeito à Literacia para a Saúde do seu público (Friedman, Tanner \& Rose, 2013; Hinnant \& LenRios, 2009; Tanner, Friedman, \& Zheng, 2015; Wilson, Robertson, McElduff, Jones \& Henry, 2010). Entendese, aqui, por Literacia para a Saúde o desenvolvimento da capacidade de obter, processar e compreender informações sobre Saúde que são necessárias para tomar decisões apropriadas (Magalhães, Lopes \& Costa-Pereira, 2017; Nutbeam \& Lloyd, 2020).

Portador de toda esta responsabilidade, o Jornalismo em Saúde trabalha assuntos que passam pela investigação biomédica e clínica, como também pelas políticas de Saúde, pelo bem-estar geral e pela Saúde Pública (Hallin \& Briggs, 2014; Schwitzer, 2009). Toda esta área alargada de atuação tem como consequência uma pesada carga de trabalho que, em tempos de crise e de pandemia, evidenciam graves preocupações relativas ao exercício do Jornalismo (Gomes, 2020).

\section{A mediatização de uma crise de Saúde Pública: o Jornalismo em tempos de COVID-19}

Ainformação é um recurso essencial para a sociedade, adquirindo especial importância em contextos de crise, como é o caso da crise de Saúde Pública gerada pela pandemia de COVID-19. Somente quando detentora de conhecimento é que a população pode reagir e adaptarse adequadamente às circunstâncias. A informação é, portanto, uma ferramenta que pode, por um lado, ajudar a reduzir os níveis de ansiedade e incerteza na população ou, por outro lado, contribuir para o pânico e para o caos generalizado (Casero- Ripollés, 2020; Wang, Lu, Ko, Chen, Li, Chang \& Yen, 2020).

Em contexto pandémico, o Jornalismo adquire, então, uma função primordial na sociedade, estabelecendo uma ligação entre o campo da Saúde e o cidadão comum (Gomes, 2019). Esta função de mediador robustece 0 papel de educador para a Saúde (Friedman, Tanner \& Rose, 2013; Hinnant \& Len-Rios, 2009; Tanner et al., 2015). Com o surgimento de uma nova doença, os media concentram-se em explicá-la ao público, apresentando os seus sintomas, consequências, assim como formas de a prevenir (Melki, Tamim, Hadid, Farhat, Makki, Ghandour \& Hitti, 2020). Ainda que já tenhamos experienciado outros surtos como o do Ébola e do H1N1, a COVID-19 é a primeira pandemia na era dos media sociais. Isto significa que as informações sobre esta doença tendem a espalhar-se a grande velocidade e com um controlo limitado. Esta dinâmica favorece a comunicação direta entre especialistas e público (Mora-Rodríguez \& MeleroLópez, 2021; Viswanath, Lee \& Pinnamaneni, 2020).

Num panorama de mudanças repentinas nas rotinas de produção noticiosa, cabe ao Jornalismo adaptar-se. A crise gerada pela COVID-19 trouxe novos desafios, equacionando-se não apenas as potencialidades do Jornalismo, como também as suas fragilidades e efeitos negativos. $O$ elevado número de notícias falsas divulgadas em contextos pandémicos veio demonstrar o impacto da chamada desinformação (Tejedor, Cervi, Tusa, Portales \& Zabotina, 2020). Como refere Andreu Casero-Ripollés, surgiu "um sistema complexo que se caracteriza pela proliferação de canais e plataformas, uma multiplicação de provedores de informação" (2020, p. 2) e como resultado, experiencia-se "um ecossistema de notícias saturado, onde informar não é tarefa fácil" (Casero-Ripollés, 2020, p. 2). As informações que circulam nas redes sociais não são filtradas pelos chamados gatekeepers, pelo que os media adquirem um novo papel: contrariar a sobrecarga de informação e 0 aumento da desinformação (Mora-Rodríguez \& MeleroLópez, 2021; Sánchez-Duarte \& Rosa, 2021; Tejedor et. al., 2020; Viswanath, Lee \& Pinnamaneni, 2020). A própria escassez de certezas científicas sobre a COVID-19 
fomenta uma comunicação vulnerável e propícia a esta desinformação (Sánchez-Duarte \& Rosa, 2021; Alcázar, 2020; Jaiswal, LoSchiavo \& Perlman, 2020).

0 uso da Internet enquanto fonte de informação sobre Saúde cresce diariamente (Rodríguez-González, 2021). A consolidação do uso de plataformas digitais criou um sistema mediático híbrido, em que coexistem novos e antigos meios de comunicação (Casero-Ripollés, 2020). Esta coexistência acontece, por vezes de forma harmoniosa, mas também de um modo antagónico. Wang e colegas (2020) indicam que a Internet e os media tradicionais são as principais fontes de informação para a sociedade em caso de surtos ou pandemias. Há, portanto, uma complementaridade entre estes diferentes modos de comunicar, pelo que a audiência absorve uma espécie de informação combinada, ou seja, informação proveniente de diferentes meios de comunicação (Casero-Ripollés, 2020). A Internet e as redes sociais adotam, então, um papel particular, pelo que a adaptação do Jornalismo pode também passar por aí.

Numa investigação sobre a cobertura mediática da COVID-19 em Espanha, Lázaro-Rodríguez e HerreraViedma (2020) concluem que, em contexto de alerta geral, o interesse do público sobre 0 assunto aumenta consideravelmente. Costa-Sánchez e López-Garcia (2020) corroboram esta ideia, referindo que este interesse tem consequências diretas nas decisões dos media. Nestes contextos, cidadãos habitualmente menos interessados, revelam um maior consumo de notícias (Casero-Ripollés, 2020), pelo que a informação científica ganha maior destaque enquanto fonte de conhecimento sobre a COVID-19 (Lázaro-Rodriguez \& Herrera-Viedma, 2020). Por outras palavras, a sociedade adquire maior importância no processo de produção noticiosa, fortalecendo a linha de pensamento que atribui ao Jornalismo uma função ativa no exercício da cidadania (Casero-Ripollés, 2020; Kovach \& Rosenstiel, 2007; Martins, 2010).

Estes e outros estudos indicam que a cobertura mediática durante uma pandemia se concentra em aspetos como a apresentação de números (ou estatísticas), a identificação de formas de prevenir a doença, assim como a explicação sobre o processo de transmissão do vírus. Estas informações são, geralmente, apresentadas com 0 intuito de educar a população (Melki et al., 2020). Mas, para promover com eficácia comportamentos preventivos, é fundamental que se explique não só 'o que fazer', mas também o 'por que fazer'. Isto deve acontecer de forma clara, consistente e repetida (Noar \& Austin, 2020).

Pensando na forma como é, tendencialmente, realizada a cobertura noticiosa de surtos ou pandemias, será também de considerar a tendência para mediatizar a morte. Uma vez mais, equacionam-se os objetivos do Jornalismo em Saúde, ou seja, se lhe cabe informar sobre questões de Saúde, cabe-lhe também relatar os casos de rutura extrema: a morte (Gomes, 2020; Gomes \& Lopes, 2016). Tal como refere Gary Kreps, "não é fácil comunicar a morte, mas as incertezas que cercam a morte exigem uma comunicação sensível e atenciosa" (2003, pp. 165-166). De facto, o modo de encarar a morte tem vindo a alterar-se, nomeadamente no que diz respeito ao próprio espaço: "a morte como acontecimento da vida passou do domínio familiar para o domínio dos técnicos de saúde" (Macedo, 2010, p. 197). Com isto, o Jornalismo foi-se adaptando, tornando-se mais sensivel e apoiado por testemunhos pessoais que "transmitem informação pormenorizada sobre temas difíceis, como a morte ou a doença", e que tocam o público "de uma forma que outros estilos noticiosos não conseguem" (Araújo \& Lopes, 2013, p.17).

\section{A importância das fontes de informação}

Não obstante as dificuldades e preocupações identificadas, certo é que o futuro do Jornalismo em Saúde dependerá, de entre outros aspetos, da relação que os jornalistas estabelecerem com as suas fontes de informação, nomeadamente, cientistas e profissionais de Saúde (Gomes, 2020; Schwitzer, 2010). As fontes de informação são, pois, a matéria-prima que dá início ao processo de produção noticiosa, pelo que a construção da notícia requer um conjunto de negociações e uma estreita cooperação entre fontes e jornalistas (Lewis, Williams \& Franklin, 2008; Sigal, 2008).

É sabido que todas as fontes de informação têm interesses, pelo que a interação entre jornalistas e fontes deve acontecer com base num conjunto de questões: 0 tipo de fonte e o conhecimento da informação que the confere o papel de fonte, a (in)dependência do jornalista em relação a esta e a existência de objetivos comuns (Lopes, Ruão, Marinho \& Araújo, 2012). A boa relação entre estes intervenientes sustentará o processo de construção das notícias de Saúde.

No campo particular da Saúde, esta relação entre jornalistas e fontes torna-se ainda mais complexa. Procurando simplificar a informação para que o cidadão 
comum a entenda, os jornalistas tentam transformar 0 saber científico em algo mais apelativo, desvalorizando dados que thes parecem menos relevantes. Esta descomplexificação do conhecimento científico nem sempre é entendida e bem-recebida pelos cientistas. Por sua vez, os especialistas também não são sempre dotados de competências comunicativas que lhes permitam transmitir o conhecimento de um modo simples e percetível para o cidadão comum (Allgaier, Dunwoody, Brossard, Yin-Yueh \& Peters, 2013; Brilha, 2004; Schmidt, 2008; Teixeira, 2002).

Como referem Mora-Rodríguez e Melero-López, num contexto pandémico, como o causado pelo novo Coronavírus, é espectável que os líderes políticos assumam um papel preponderante, na medida em que têm obrigações de cariz administrativo e porque são os criadores da própria informação oficial (Mora-Rodríguez \& Melero-López, 2021). Assim como os líderes políticos, também os especialistas "adquirem uma importância vital como fontes de informação" (Mora-Rodríguez \& MeleroLópez, 2021, p. 73).

Em Portugal, estudos desenvolvidos sobre a mediatização da Saúde sugerem uma forte presença de fontes governamentais (ou oficiais) e de fontes especializadas institucionais que representam organizações prestadoras de saúde (Lopes, Ruão, Marinho \& Araújo, 2012). Esta situação parece, pois, influenciar a forma como as informações são recebidas, assim como as atitudes que a sociedade toma após a receção da notícia (Gomes, 2020). Perante isto, os media tendem a contactar sempre as mesmas fontes de informação, escolhendo-as em função das suas competências comunicativas, ou seja, socorrem-se das fontes que "apresentam um registo da ordem do 'pensar', excluindo quase sempre o cidadão comum e o paciente ou seu familiar, que têm um discurso mais da ordem do 'sentir'" (Lopes, Ruão, Marinho \& Fernandes, 2013, p. 598). O resultado destas dificuldades é a promoção da existência de confrarias e de elites, assim como de grupos de fontes deixadas à margem e no silêncio (Lopes, 2007).

\section{Metodologia}

O estudo apresentado procurou contribuir para uma melhor perceção da cobertura mediática da COVID-19 em Portugal, nomeadamente em jornais de expressão online. Com esse propósito, pretendeu-se responder à seguinte questão de partida: De que modo o Jornalismo online português mediatiza a COVID-19?
No que diz respeito à seleção das unidades de análise, seguiu-se uma amostragem não probabilística por semanas compostas. Partiu-se da análise dos artigos noticiosos sobre a COVID-19 em quatro edições online: Jornal de Notícias (JN), fundado em 1888; Público, fundado em 1990, Observador, fundado em 2014, e Notícias ao Minuto (NM), fundado em 2012. Os jornais foram selecionados de modo a incluir: edições com expressão exclusivamente online; edições com versão em papel; jornais de referência; assim como jornais de cariz mais popular.

$\mathrm{Na}$ seleção e recolha dos artigos, o acesso aos vários jornais aconteceu propositada e sistematicamente no período da tarde, uma vez que as conferências de imprensa da Direção-Geral da Saúde tinham lugar à hora do almoço e configuravam um motivo de noticiabilidade nas publicações seguintes. Nesta seleção foram apenas considerados os primeiros dez artigos em acesso aberto da primeira página de cada jornal. A análise decorreu entre 1 de abril e 12 de maio de 2020. Desta seleção resultaram 280 textos noticiosos.

Trata-se, portanto, de um estudo de mapeamento, que privilegiou a análise quantitativa dos dados, centrada na estatística descritiva univariada. As variáveis consideradas na análise foram as seguintes: tipo (notícia; reportagem; crónica/opinião; entrevista; sondagem) e tamanho do artigo (breve; médio; extenso); presença de formas imagéticas (fotografia; infografia; gráfico; vídeo); presença nas redes sociais (página no Facebook do próprio jornal) e apps dos jornais (versão móvel do jornal); local de notícia (nacional; internacional-fora da Europa; Europa; vários); finalidade do texto (informativo; interpretativo; divulgativo; opinativo; outro); autoria do texto (jornalistas; agências; redação; sem referência; outro); temática (contagem; medidas; social; política; consequências; investigação; economia; doença; educação; desporto; tratamentos; emprego; religião; outra); presença de fontes de informação (com ou sem fontes) e número de fontes de informação (uma; duas; três; quatro; cinco ou mais; sem fontes). Em alguns aspetos identificados nos artigos noticiosos, houve espaço para uma análise qualitativa, desenvolvendo-se uma breve análise ao conteúdo dos textos.

Em termos metodológicos, também o método comparativo foi uma ferramenta utilizada, na medida em que, durante a análise dos dados, esteve implícita uma comparação relativamente ao modo como os quatro jornais mediatizaram a COVID-19. Desta forma, e seguindo a referência de Schneider e Schimitt, procurou-se "descobrir 
regularidades, perceber deslocamentos e transformações (...) identificando continuidades e descontinuidades, semelhanças e diferenças" (1998, p. 49).

\section{Da mediatização da COVID-19 em Portugal}

COVID-19: notícias de um Portugal pandémico

A análise das variáveis trabalhadas permite construir uma caracterização sustentada dos textos noticiosos em causa. Num primeiro momento, é possível afirmar que a mediatização da COVID-19 nos quatro jornais estudados acontece, essencialmente, através de notícias médias de âmbito nacional.

Relativamente ao tipo de artigo, e à semelhança do que vem sendo registado em estudos anteriores, evidencia-se uma clara predominância de notícias (227), em detrimento de formatos mais desenvolvidos, como a reportagem (39), ou mais personalizados como a crónica (6) e a entrevista (2) (tabela 1).

Observa-se que o Público é o jornal que mais recorre a reportagens, com 20 casos, seguindo-se o Jornal de Notícias, com 10 casos. O Observador destaca-se por ser o único a publicar ${ }^{1}$ artigos de opinião sobre a COVID-19 na primeira página, assim como é o único a publicar entrevistas. O Jornal de Notícias também é merecedor de destaque na análise a esta variável por publicar uma sondagem.

Contrariamente ao que seria de esperar, os textos são maioritariamente médios (130 casos) ou extensos (117 casos), ou seja, as notícias são escritas com quatro ou mais parágrafos. Nos 280 textos, apenas 33 são breves (tabela 2). Um olhar por jornal permite-nos identificar algumas tendências. Um primeiro aspeto é o facto de todos os jornais publicarem menos artigos breves. Outro aspeto diz respeito aos artigos de dimensão média, em que se destacam os jornais Público e o Notícias ao Minuto, com 37 e 34 artigos, respetivamente. Quanto aos textos extensos, são o Jornal de Notícias e o Observador que registam maiores valores, com 33 casos cada um. Ainda assim, não se pode afirmar que existe uma grande distinção entre os valores apresentados entre jornais relativamente a textos médios e extensos.

Um outro ponto a destacar, e que contraria estudos anteriores, resulta do cruzamento entre as variáveis tipo de artigo e dimensão de artigo. Por norma, as notícias são mais breves que as reportagens e as entrevistas. 0 que estes resultados nos indicam é que a mediatização da COVID-19 é feita com notícias médias ou extensas,

TE importante realçar que este estudo apenas considera as primeiras 10 notícias de cada página. contrariando a ideia de que os textos extensos são normalmente reportagens.

Relativamente à presença de diferentes formas imagéticas, a análise aponta para a utilização de fotografias em todos os textos publicados. No entanto, em alguns casos, a fotografia é complementada com infografias, gráficos ou vídeos. De um modo sucinto, pode dizer-se que as fotografias ilustram, as infografias e os gráficos explicam e os vídeos complementam a informação apresentada em texto (tabela 3).

Observando a tabela 3, é possível identificar-se diferentes perfis. Apesar de ser um jornal exclusivamente online, o Notícias ao Minuto, por norma, não recorre a formatos muito inovadores, ficando-se pela fotografia (em todos os artigos) e apresentando apenas duas infografias e dois gráficos. Contrariamente a este perfil, - Observador socorre-se frequentemente de infografias (20 casos) e de gráficos (5 casos) para explicar as informações apresentadas no texto noticioso. No que respeita às infografias, situação semelhante acontece no Jornal de Notícias, apesar dos distintos perfis de cada publicação. O Público é o jornal que se destaca pela maior presença de vídeos. A utilização quase exclusiva de vídeos nos jornais originalmente em papel é um aspeto a considerar se estivermos a refletir sobre o modo como cada um se tem adaptado às novas tecnologias e possibilidades de comunicar com o público.

Procurou-se identificar a presença dos artigos nas páginas do Facebook de cada jornal, assim como nas respetivas aplicações (tabela 4).

Esta variável evidenciou uma clara aposta na publicação das notícias nas aplicações dos jornais. 0 Jornal de Notícias é o exemplo mais claro disso, uma vez que, em 70 artigos analisados, 69 estavam presentes na versão móvel do jornal. Por outro lado, o mesmo não acontece com o recurso às páginas no Facebook. Uma vez mais é o Jornal de Notícias que se destaca, com a presença de 53 artigos na sua página nesta rede social. O Público e o Observador são aqueles que menor se refletem nas páginas do Facebook, com apenas 33 e 35 artigos, respetivamente.

Ainda assim, importa lembrar que o acesso aos vários jornais aconteceu propositada e sistematicamente no período da tarde e que foram apenas considerados os primeiros dez artigos em acesso aberto da primeira página de cada jornal. Por outras palavras, os artigos identificados no site de cada jornal podem ter sido partilhados nas aplicações e nas páginas do Facebook nas horas ou dias seguintes à recolha. 
Tabela 1. O tipo de artigo nos jornais.

\begin{tabular}{|c|c|c|c|c|c|}
\hline Tipo de artigo & JN & Público & Observador & NM & Total \\
\hline Notícia & 55 & 50 & 55 & 67 & 227 \\
\hline Reportagem & 10 & 20 & 7 & 2 & 39 \\
\hline Crónica/Opinião & 0 & 0 & 6 & 0 & 6 \\
\hline Outro & 4 & 0 & 0 & 1 & 5 \\
\hline Entrevista & 0 & 0 & 2 & 0 & 2 \\
\hline Sondagem & 1 & 0 & 0 & 0 & 1 \\
\hline Total & 70 & 70 & 70 & 70 & 280 \\
\hline
\end{tabular}

Tabela 2. A dimensão do artigo nos jornais.

\begin{tabular}{|c|c|c|c|c|c|}
\hline $\begin{array}{l}\text { Jamanhol } \\
\text { do artigo }\end{array}$ & JN & Público & Observador & NM & Total \\
\hline $\begin{array}{l}\text { Breve (1 a } 3 \\
\text { parágrafos) }\end{array}$ & 6 & 13 & 9 & 5 & 33 \\
\hline $\begin{array}{l}\text { Médio (4 a } 10 \\
\text { parágrafos) }\end{array}$ & 31 & 37 & 28 & 34 & 130 \\
\hline $\begin{array}{l}\text { Extenso (10 ou } \\
\text { mais parágrafos) }\end{array}$ & 33 & 20 & 33 & 31 & 117 \\
\hline Total & 70 & 70 & 70 & 70 & 280 \\
\hline
\end{tabular}

Tabela 3. A presença de formas imagéticas nos jornais.

\begin{tabular}{|l|c|c|c|c|}
\hline $\begin{array}{l}\text { Formas } \\
\text { imagéticas }\end{array}$ & JN & Público & Observador & NM \\
\hline Fotografia & 70 & 70 & 70 & 70 \\
\hline Infografia & 16 & 10 & 20 & 2 \\
\hline Gráfico & 0 & 1 & 5 & 2 \\
\hline Vídeo & 2 & 4 & 1 & 0 \\
\hline
\end{tabular}

Tabela 4. A presença nas redes sociais e apps nos jornais.

\begin{tabular}{|l|c|c|c|c|c|}
\hline Jornal & JN & Público & Observador & NM & Total \\
$\begin{array}{l}\text { Redes sociais/ } \\
\text { apps }\end{array}$ & & & & & \\
\hline Facebook & 53 & 33 & 35 & 46 & \\
\hline Aplicação do jornal & 69 & 62 & 53 & 57 & \\
\hline Total & 70 & 70 & 70 & 70 & 280 \\
\hline
\end{tabular}




\section{Para informar sobre o país}

A variável local de notícia dá forma a esta caracterização dos textos e é precisamente a importância dada à situação do país que é visível nos resultados obtidos: 197 dos 280 artigos trabalhados dizem respeito a notícias nacionais, ou seja, textos que retratam o estado do país. Com valores já bem distantes destes, a Europa é o segundo local de notícia mais registado, com 45 artigos. Os textos de cariz internacional obtêm valores mais reduzidos, registando-se apenas 33 casos.

Estes dados apontam para uma preocupação com o contexto pandémico a nível nacional, mas também em países mais próximos como é o caso de Espanha. Neste contexto, não poderemos esquecer as notícias que relatam o encerramento de fronteiras, assim como a influência que a Europa e as suas políticas podem ter no desenvolvimento de medidas a adotar contra esta pandemia (tabela 5).

A distribuição dos artigos por indicadores é bastante semelhante em todos os jornais. Ainda assim, importa referir que o Observador e o Notícias ao Minuto são aqueles que mais publicam sobre a Europa. $O$ recurso destes jornais, de expressão exclusivamente online, a informações provenientes de agências noticiosas pode ser uma explicação para este facto. Contudo, os dados obtidos não nos permitem confirmar esta suspeita.

Não obstante a sua finalidade essencialmente informativa, os textos jornalísticos estudados podem apontar para outras funções do Jornalismo em Saúde. Relativamente à finalidade do texto, dos 280 artigos, 166 foram efetivamente identificados como textos informativos. Trata-se, pois, de artigos que procuram apresentar os dados sobre a evolução da doença ou que apresentam novas medidas do Governo, ou seja, são textos que se limitam a dar a notícia. Por sua vez, 83 artigos foram considerados interpretativos, ou seja, respondem à finalidade de explicar um determinado aspeto da pandemia. Por outras palavras, estes textos não se limitam a informar e procuram aprofundar a informação, indo além da novidade. Complementam a informação com dados adicionais, tais como a presença de vários pontos de vista, de distintas formas imagéticas e de diversas fontes de informação (tabela 6).

Observando os dados por jornais, evidencia-se a presença de mais artigos interpretativos no Público e no Jornal de Notícias (25 casos cada um). É também nestes dois jornais que encontramos um maior número de textos divulgativos, ou seja, textos que procuram explicar a informação científica, nomeadamente como atua 0 vírus, como podem funcionar as vacinas, etc. A estes textos podem estar associadas formas imagéticas como a infografia e os gráficos.

Esta análise reforça algumas ideias apresentadas relativamente à variável tipo de artigo. Ainda que não haja uma relação direta e unilateral entre o tipo de artigo e a sua finalidade, associamos, pois, os textos informativos às notícias, assim como podemos estabelecer uma associação entre os artigos interpretativos e as reportagens. São também as reportagens que mais recorrem a diferentes formas imagéticas (vídeos e infografias).

Os resultados apontam, também, para uma predominância de textos cuja autoria é imputada aos jornalistas (171 textos) que, em espaço apropriado, são identificados como autores dos textos. Verifica-se, ainda, um elevado número de textos replicados de agências de comunicação. Nestes casos, não se identifica qualquer tratamento por parte dos jornais que publicam a notícia (tabela 7). Isto acontece em 50 artigos, 31 deles publicados no Notícias ao Minuto. É também no Noticias ao Minuto que mais se identificam textos com autoria atribuída à redação, com 22 casos. Nestes textos, torna-se impossível identificar o autor. Com um valor bem mais reduzido, registam-se 17 artigos sem referência aos autores, sendo 9 dos casos no Jornal de Notícias.

Tabela 5. O local de notícia nos jornais

\begin{tabular}{|l|c|c|c|c|c|}
\hline Local de notícia & JN & Público & Observador & NM & Total \\
\hline Nacional & 50 & 51 & 50 & 46 & 197 \\
\hline $\begin{array}{l}\text { Internacional (fora } \\
\text { da Europa) }\end{array}$ & 9 & 8 & 8 & 8 & 33 \\
\hline Europa & 10 & 7 & 12 & 16 & 45 \\
\hline Vários & 1 & 4 & 0 & 0 & 5 \\
\hline Total & 70 & 70 & 70 & 70 & 280 \\
\hline
\end{tabular}


Tabela 6. A finalidade do texto nos jornais.

\begin{tabular}{|l|c|c|c|c|c|}
\hline \multicolumn{1}{|c|}{ Jornal } & JN & Público & Observador & NM & Total \\
\hline Informativo & 42 & 35 & 41 & 48 & 166 \\
\hline Interpretativo & 17 & 25 & 25 & 16 & 83 \\
\hline Divulgativo & 11 & 10 & 2 & 6 & 29 \\
\hline Opinativo & 0 & 0 & 1 & 0 & 1 \\
\hline Outro & 0 & 0 & 1 & 0 & 1 \\
\hline Total & 70 & 70 & 70 & 70 & 280 \\
\hline
\end{tabular}

Tabela 7. A autoria nos jornais.

\begin{tabular}{|l|c|c|c|c|c|}
\hline Jutoria & JN & Público & Observador & NM & Total \\
\hline Jornalistas & 43 & 58 & 53 & 17 & 171 \\
\hline Agências & 6 & 5 & 8 & 31 & 50 \\
\hline Redação & 11 & 5 & 3 & 22 & 41 \\
\hline Sem referência & 9 & 2 & 6 & 0 & 17 \\
\hline Outro & 1 & 0 & 0 & 0 & 1 \\
\hline Total & 70 & 70 & 70 & 70 & 280 \\
\hline
\end{tabular}

\section{As contagens da COVID-19}

Como referido, não raras vezes, o Jornalismo mune-se de um conjunto de dados numéricos para dar força às informações noticiadas. Na cobertura da COVID-19 em Portugal esta regra não teve exceção.

Evidencia-se uma tendência para a contagem de infetados e de mortos pelo novo Coronavírus. Apesar desta necessidade de contabilizar mortes e infeções (59 textos), os artigos noticiosos procuraram, também, informar sobre medidas políticas de controlo e de prevenção do vírus (58 textos) (tabela 8).

Os dados obtidos apontam para uma realidade já observada em estudos sobre Comunicação em Saúde. De facto, diariamente, os media procuram apresentar em números, o resultado fatal da pandemia, familiarizando o público com esta triste realidade (Gomes \& Lopes, 2016). Nas várias semanas em análise, esta ideia é percetível na publicação de títulos como os apresentados na tabela 9 .

A tabela anterior realça duas situações: a existência da mesma informação, nas mesmas datas, nos diferentes jornais e a importância dos números da vizinha Espanha. 0 primeiro aspeto sugere que os distintos media funcionam de maneira semelhante, transmitindo informações fornecidas por fontes oficiais: nestes casos, os boletins da DGS. É também possível confirmar o retrato que os jornais online fazem da carga política e económica que a COVID-19 tem na sociedade portuguesa. Depois das notícias sobre temas políticos (23 casos) e económicos (15 casos), estão também os textos noticiosos sobre as consequências da pandemia na sociedade (18 casos) e os textos sobre investigações em desenvolvimento para a criação de uma vacina contra a COVID-19 (16 casos). Se estes temas se destacam pela sua maior frequência nos jornais, por outro lado, verificam-se reduzidos valores de textos sobre tratamentos (2 casos), efeitos da pandemia na educação (4 casos), no emprego ( 2 casos) e na religião (1 caso).

Conclui-se, ainda, que os quatro jornais se concentram nos mesmos assuntos: contagem, medidas, social e outras. Ainda assim, determinados jornais ganham destaque em certas temáticas: o Notícias ao Minuto aposta em textos sobre investigação (7 casos), o Público e o Observador tratam assuntos relacionados com a Economia ( 6 artigos em cada um dos jornais) e o Jornal de Notícias trabalha mais sobre as consequências (7 casos). 
Tabela 8. A temática nos jornais.

\begin{tabular}{|l|c|c|c|c|c|}
\hline \multicolumn{1}{|c|}{ Jornal } & JN & Público & Observador & NM & Total \\
\hline Conática & & & & & 18 \\
\hline Medidas & 10 & 14 & 17 & 14 & 59 \\
\hline Outras & 15 & 14 & 15 & 14 & 38 \\
\hline Social & 13 & 6 & 5 & 2 & 30 \\
\hline Política & 3 & 6 & 9 & 6 & 23 \\
\hline Consequências & 7 & 6 & 4 & 3 & 18 \\
\hline Investigação & 4 & 4 & 4 & 7 & 16 \\
\hline Economia & 1 & 4 & 1 & 2 & 15 \\
\hline Doença & 1 & 6 & 6 & 0 & 10 \\
\hline Educação & 0 & 1 & 2 & 1 & 4 \\
\hline Desporto & 2 & 0 & 1 & 0 & 3 \\
\hline Tratamentos & 1 & 1 & 0 & 0 & 2 \\
\hline Emprego & 0 & 2 & 0 & 0 & 2 \\
\hline Religião & 0 & 0 & 1 & 1 & 2 \\
\hline Total & 70 & 70 & 70 & 70 & 280 \\
\hline
\end{tabular}

Tabela 9. Títulos que referem contagem de mortos e infetados.

\begin{tabular}{|l|l|l|}
\hline \multicolumn{1}{|c|}{ Título } & \multicolumn{1}{|c|}{ Jornal } & Data \\
\hline $\begin{array}{l}\text { Há } 187 \text { mortes por Covid-19 em Portugal. Mais de oito mil } \\
\text { infetados }\end{array}$ & Jornal de Notícias & 1 de abril \\
\hline Covid-19: Portugal tem 187 mortes e 8251 infectados & Público & 1 de abril \\
\hline $\begin{array}{l}\text { Boletim DGS. Curva dos novos casos volta a descer no dia em } \\
\text { que se registaram mais mortes no país }\end{array}$ & Observador & 1 de abril \\
\hline $\begin{array}{l}\text { Espanha ultrapassa os } 100 \text { mil infetados. E regista mais } 864 \\
\text { mortos }\end{array}$ & Notícias ao Minuto & 1 de abril \\
\hline $\begin{array}{l}\text { Morreram } 409 \text { pessoas de covid-19 em Portugal. Há 13.956 } \\
\text { casos confirmados }\end{array}$ & Público & 9 de abril \\
\hline $\begin{array}{l}\text { Boletim DGS. 13.956 casos e mais 29 mortos. Portugal } \\
\text { ultrapassa as } 400 \text { vítimas mortais }\end{array}$ & Observador & 9 de abril \\
\hline $\begin{array}{l}\text { Covid-19. Há 13.956 infetados em Portugal. Já morreram 409 } \\
\text { pessoas }\end{array}$ & Notícias ao Minuto & 9 de abril \\
\hline $\begin{array}{l}\text { Morreram mais } 683 \text { pessoas em Espanha e superam-se as 15 } \\
\text { mil mortes }\end{array}$ & Jornal de Notícias & 9 de abril \\
\hline Covid-19: Espanha ultrapassa a cifra dos 15 mil mortos & Notícias ao Minuto & 9 de abril \\
\hline Mortes em tempo de Covid ultrapassam ano letal de 2018 & Jornal de Notícias & 25 de abril \\
\hline $\begin{array}{l}\text { Número de mortes volta a subir em Espanha. Foram 378 nas } \\
\text { últimas 24h }\end{array}$ & Notícias ao Minuto & 25 de abril \\
\hline $\begin{array}{l}\text { Espanha regista mesmo número de mortos há dois dias } \\
\text { consecutivos: } 164\end{array}$ & Público & 5 de maio \\
\hline
\end{tabular}




\section{Os políticos que dominam a Saúde}

Passada a análise às variáveis que qualificam o texto noticioso, chega-se às variáveis que dizem respeito às fontes de informação. Num primeiro momento, importa perceber se as fontes estão ou não presentes nos artigos noticiosos, para depois quantificá-las, identificálas e perceber o que representam na mediatização da COVID-19.

Dos 280 artigos analisados, 241 apresentam, pelo menos, uma fonte de informação e 39 não fazem referência à origem da informação prestada. Os dados refletem algum cuidado dos jornalistas e/ou dos media em atribuir responsabilidades no que toca às informações difundidas (tabela 10).

Paralelamente à forte presença de fontes nos artigos, o número de fontes não é tão animador. Grande parte dos textos (152) apresenta somente uma fonte de informação e os resultados vão diminuindo conforme o número de fontes aumenta. Este dado evidencia uma falta de contraditório, ou seja, as fontes que têm voz nestes artigos noticiosos são únicas e os seus pontos de vista são exclusivos, revelando a ausência de outras perspetivas.

Apesar de ser um dado recorrente em estudos anteriores, o facto é que, numa área tão específica como esta, o público carece de mais e maiores explicações. Quanto menos fontes forem ouvidas, em menor número serão os esclarecimentos de especialistas na área e menor serão também as perspetivas abordadas (tabela 11).

É possível fazer-se algumas considerações sobre o comportamento de cada jornal. Relativamente à ausência de fontes, os resultados evidenciam um comportamento idêntico entre os vários jornais, sendo que os valores de artigos sem fontes de informação variam entre 9 e 11 casos. O Notícias ao Minuto e o Jornal de Notícias são aqueles que mais publicam artigos com apenas uma fonte de informação, registando-se 47 e 40 textos, respetivamente. Por sua vez, o Público é o jornal com mais textos com referência a várias fontes: 11 textos com três fontes e 10 textos com cinco ou mais fontes.
É também o Público aquele que mais apresenta artigos sem qualquer fonte de informação (11 textos).

A análise qualitativa destes 280 artigos noticiosos contraria os estudos sobre Jornalismo em Saúde e fontes de informação que foram mencionados no enquadramento teórico deste artigo. $\mathrm{Na}$ realidade, os dados reunidos indicam um panorama distinto relativamente à cobertura noticiosa da COVID-19 em Portugal. Apesar de se tratar de textos de Saúde, as fontes de informação mais identificadas não fazem parte deste campo do conhecimento. Pelo contrário, são as fontes políticas que dominam. Assistimos, pois, à participação assídua do primeiro-ministro, António Costa, do presidente da República, Marcelo Rebelo de Sousa, e de representantes ou deputados de outros partidos. É, ainda, evidente uma forte presença de documentos oficiais, como é o caso dos boletins diários da DireçãoGeral da Saúde. A presença destas fontes de informação encontra justificação no que facto de grande parte dos artigos divulgarem medidas e políticas do Governo para controlar e prevenir o crescimento do número de casos de COVID-19 em Portugal.

Com este enquadramento, é possível inferir que se mantém a presença das chamadas elites de poder também mencionadas no enquadramento teórico. Tratase, pois, de fontes oficiais que respondem pelo Governo. Apesar desta presença de fontes do Governo, seria espectável uma maior participação de fontes oficiais do campo da Saúde, como é o caso de Marta Temido, ministra da Saúde, e de Graça Freitas, diretora-geral da Saúde. Mesmo sendo citadas algumas vezes, não têm o protagonismo de António Costa.

A reduzida presença da ministra da Saúde e da diretorageral da Saúde explica-se pelo facto de os jornais terem preferência pelos boletins da DGS, informação que ambas apresentavam ao país diariamente em conferência de imprensa. Uma vez que compilam os dados diários - como a contagem de infetados, mortos e recuperados - de uma forma sistemática e em distintos formatos, estes boletins são uma fonte de informação atraente para os jornalistas.

Tabela 10. A presença de fontes nos jornais.

\begin{tabular}{|l|c|c|c|c|c|}
\hline $\begin{array}{l}\text { Jornal } \\
\text { Presença de } \\
\text { fontes }\end{array}$ & JN & Público & Observador & NM & Total \\
\hline Com fontes & 61 & 59 & 61 & 60 & 241 \\
\hline Sem fontes & 9 & 11 & 9 & 10 & 39 \\
\hline Total & 70 & 70 & 70 & 70 & 280 \\
\hline
\end{tabular}


Tabela 11. O número de fontes nos jornais.

\begin{tabular}{|l|c|c|c|c|c|}
\hline \multicolumn{1}{|c|}{ Jornal } & JN & Público & Observador & NM & Total \\
\hline Nma fonte & 40 & 27 & 38 & 47 & 152 \\
\hline Duas fontes & 9 & 10 & 8 & 11 & 38 \\
\hline Três fontes & 6 & 11 & 8 & 1 & 26 \\
\hline Quatro fontes & 1 & 1 & 5 & 0 & 7 \\
\hline $\begin{array}{l}\text { Cinco ou mais } \\
\text { fontes }\end{array}$ & 5 & 10 & 2 & 1 & 18 \\
\hline Sem fontes & 9 & 11 & 9 & 10 & 39 \\
\hline Total & 70 & 70 & 70 & 70 & 280 \\
\hline
\end{tabular}

\section{Conclusões}

No final do ano de 2019, uma pandemia de origem chinesa causada pelo novo vírus SARS-CoV-2, veio transformar o panorama sanitário a nível mundial. A população global viuse perante uma crise de Saúde Pública e, neste contexto pandémico, a informação tornou-se essencial, pelo que 0 Jornalismo adquiriu uma função primordial na sociedade, estabelecendo uma ligação entre o complexo campo da Saúde e o cidadão comum (Gomes, 2019). A crise gerada pela COVID-19 trouxe, portanto, novos desafios, equacionando-se as potencialidades do Jornalismo.

Com o objetivo de responder à pergunta De que modo o Jornalismo online português mediatiza a COVID-19?, esta análise permitiu uma caracterização dos artigos, assim como a identificação das fontes de informação que mais foram chamadas a público.

A mediatização da COVID-19 em Portugal não apresentou grandes divergências relativamente às conclusões de estudos anteriores sobre Jornalismo em Saúde. Verificou-se, no entanto, a consolidação do uso de plataformas digitais que fomentaram um sistema mediático híbrido, em que coexistem novos e antigos meios de comunicação (Casero-Ripollés, 2020). Os dados apontaram para um forte recurso a novas plataformas, nomeadamente, as redes sociais (como o Facebook) e as app dos jornais.

Este sistema híbrido é, de certa forma, o resultado de uma necessidade de adaptação do Jornalismo às carências do seu público. Com o surgimento de uma pandemia e com a escassez de informação científica sobre o tema, 0 Jornalismo alcançou um papel especial na prevenção da doença e consequente promoção da saúde.

Os resultados obtidos vieram também corroborar a ideia de que a cobertura mediática durante uma pandemia se concentra em aspetos como a apresentação de números, a identificação de formas de prevenir a doença, assim como a explicação sobre o processo de transmissão do vírus. De facto, evidenciou-se uma tendência para a publicação de artigos que se focavam na contagem de infetados, recuperados e mortos, assim como se identificaram essencialmente textos informativos e interpretativos, ou seja, textos que davam conta do modo de atuação desta doença e da forma como pode ser prevenida e combatida.

Nesta explicação da COVID-19 ao público, os jornais recorreram a variadas formas imagéticas. A fotografia esteve presente em todos os artigos noticiosos e houve também uma forte utilização da infografia como ferramenta para desconstruir esta doença. Os textos estudados evidenciaram, também, uma cobertura da COVID-19 centrada em Portugal e no espaço europeu, com especial destaque para Espanha, através de notícias sobre medidas políticas de controlo e prevenção da doença, que têm origem em Portugal e na União Europeia.

Os desafios colocados ao Jornalismo são, portanto, inúmeros e o seu futuro será definido, entre outros aspetos, pela atuação dos seus profissionais e pela relação que estes estabelecem com as suas fontes de informação (Gomes, 2020; Schwitzer, 2010). Os resultados apontaram para uma assídua presenta de fontes de informação nos textos noticiosos, apesar do reduzido número de fontes por artigo. Está, por isso, em causa o princípio do contraditório. Numa área tão específica como esta, o público carece de mais e maiores explicações.

Por fim, importa referir que, apesar de se tratar de um conjunto de textos noticiosos sobre Saúde, as fontes de informação mais identificadas não fazem parte deste campo do conhecimento. Neste contexto pandémico, os líderes políticos assumiram um papel preponderante 
enquanto decisores e criadores da informação oficial (Mora-Rodríguez \& Melero-López, 2021). Houve, portanto, um Jornalismo muito centrado na informação que as fontes de informação (essencialmente oficiais) prestavam, evitando-se textos menos objetivos como é o caso das reportagens. Esta evidência revela algum receio por parte dos jornalistas em publicar sobre um assunto ainda tão desconhecido e que envolve consequências para toda a população.

Em jeito de conclusão, e apesar de se tratar de uma investigação em constante desenvolvimento, os dados alcançados abrem portas para novas preocupações e novos desafios no estudo do Jornalismo. Trata-se da mediatização de uma pandemia sem precedentes e sem fim à vista. Os dados, as medidas e as consequências desta doença à escala mundial estão em permanente mutação, pelo que não são apenas os decisores políticos que se estão a adaptar à COVID-19. O Jornalismo também.

Do ponto de vista da investigação, torna-se imperativo apostar na manutenção de um trabalho aprofundado sobre o Jornalismo de Saúde, assim como é fundamental partilhar com os protagonistas deste processo os resultados que se tem alcançado.

\section{Financiamento}

Este trabalho é apoiado por fundos nacionais através da FCT - Fundação para a Ciência e a Tecnologia, I.P., no âmbito do projeto UIDB/00736/2020 (financiamento base) e UIDP/00736/2020 (financiamento programático).

Declaração de disponibilidade de dados

Os dados apresentados neste estudo podem ser solicitados ao autor de correspondência.

Conflito de interesse

O autor declara que não há conflito de interesse.

\section{Referências bibliográficas}

Acheson Report. (1988). Public Health in England: The Report of the Committee of Inquiry into the Future Development of the Public Health Function. London: HMSO.

Alcázar, L. (2020). La lucha contra la desinformación en la comunicación digital durante la pandemia de COVID-19: estudio de caso de El Método del Lab RTVE. RAEIC, Revista de la Asociación Española de Investigación de la Comunicación, 7(14), 78103. https://doi.org/10.24137/raeic.7.14.4

Allgaier, J., Dunwoody, S., Brossard, D., Yin-Yueh, L. \& Peters, H. (2013). Journalism and social media as means of observing the contexts of science.
BioScience, 63(4), 284-287. https://doi.org/10.1525/ bio.2013.63.4.8

Araújo, R. \& Lopes, F. (2013). A construção de significação através da emoção. Revista Comunicando Tecnologias de informação, novos media e literacia digital, 2, 17-26. Retirado de http://www. revistacomunicando.sopcom.pt/edicao/37

Brilha, J. (2004). A Geologia, os geólogos e o manto da invisibilidade. Comunicação e Sociedade, 6, 257265. https://doi.org/10.17231/comsoc.6(2004).1238

Casero-Ripollés, A. (2020). Impact of Covid-19 on the media system. Communicative and democratic consequences of news consumption during the outbreak. El Professional de la Información, 29(2), e290223.

Costa-Sánchez, C., \& López-García, X. (2020). Comunicación y crisis del coronavirus en España. Primeras lecciones. El Professional de la Información, 29(3), e290304.

Cuéllar, M. P., \& Martín-Pena, D. (2020). Tratamiento informativo de la prensa española sobre el COVID-19 antes del estado de alarma. Revista Española de Comunicación en Salud, 12(1), 218-225.

Direção-Geral da Saúde (2020). Caso de COVID-19 identificado em doente que esteve no Norte de Portugal. Retirado de https://covid19. min-saude.pt/wp-content/uploads/2020/03/ Atualiza\%C3\%A7\%C3\%A3o-de-01032020-1521.pdf

Eide, M. (2014). Accounting for Journalism. Journalism Studies, 15(5), 679-688. https://doi.org/10.1080/146 1670X.2014.891856

Friedman, D. B., Tanner, A. \& Rose, I. D. (2013). Health journalists' perceptions of their communities and implications for the delivery of health information in the news. Journal of Community Health, 39(2), 378-385. https://doi.org/10.1007/s10900-013-9774-x

George, F. (2011). Sobre o Conceito de Saúde Pública. Retirado de https://www.dgs.pt/ficheirosde-upload-2013/publicacoes-de-francisco-georgesobre-o-conceito-de-saude-publica-pdf.aspx

Gomes, E. \& Lopes, F. (2016). Doença do legionário: da mediatização da doença à contagem das mortes. In M. L. Martins, M. L. Correia \& P. Vaz (Eds.), Figurações da morte nos média e na cultura: entre o estranho e o familiar. CECS. 
Gomes, S. (2019). Jornalismo e prevenção em saúde: retratos da imprensa portuguesa entre 2012 e 2014. Tese de Doutoramento, Universidade do Minho, Braga.

Gomes, S. (2020). O Jornalismo em saúde e as fontes de informação: o caso da COVID-19 em Portugal. RAEIC, Revista de la Asociación Española de Investigación de la Comunicación, 7(14), 127149. https://doi.org/10.24137/raeic.7.14.6

Hallin, D. C. \& Briggs, C. L. (2014). Transcending the medical/media opposition in research on news coverage of health and medicine. Media, Culture \& Society, 37(1), 85-100. https://doi. org/10.1177/0163443714549090

Hinnant, A. \& Len-Rios, M. (2009). Tacit understanding of health literacy: Interview and survey research with health journalists. Science Communication, 31(1), 84-115. https://doi.org/10.1177/1075547009335345

Jaiswal, J., LoSchiavo, C. \& Perlman, D. (2020). Disinformation, Misinformation and Inequality-Driven Mistrust in the Time of COVID-19: Lessons Unlearned from AIDS Denialism. AIDS and Behavior, 24, 27762780. https://doi.org/10.1007/s10461-020-02925-y

Kovach, B. \& Rosenstiel, T. (2007). The elements of journalism: What newspeople should know and the public should expect. New York: Three Rivers Press.

Kreps, G. (2003). The Impact of Communication on Cancer Risk, Incidence, Morbidity, Mortality, and Quality of Life. Health Communication, 15(2), 161169. https://doi.org/10.1207/S15327027HC1502_4

Lázaro-Rodríguez, P. \& Herrera-Viedma, E. (2020). Noticias sobre Covid-19 y 2019-nCoV en medios de comunicación de España: el papel de los medios digitales en tiempos de confinamiento. El profesional de la información, 29(3), e290302.

Lewis, J., Williams, A. \& Franklin, B. (2008). Four rumours and an explanation: a political economic account of journalists' changing newsgathering and reporting practices. Journalism Practice, 2(1), 27-45. https:// doi.org/10.1080/17512780701768493

Lopes, F. (2007). A TV das elites. Porto: Campo das Letras.

Lopes, F. (2020). As doenças na imprensa portuguesa: retrato de uma década. In F. Lopes \& R. Araújo (Eds.),
As doenças na imprensa portuguesa: retrato de uma década (pp. 5-10). Braga: CECS.

Lopes, F., Ruão, T., Marinho, S. \& Araújo, R. (2012). A media pandemic: Influenza $A$ in Portuguese newspapers. International Journal of Healthcare Management, 5(1), 19-27. https://doi.org/10.1179/2 $047971911 Y .0000000001$

Lopes, F., Ruão, T., Marinho, S. \& Fernandes, L. (2013). $\mathrm{Na}$ saúde a palavra mediática não é dos doentes. In Atas do II Congresso Internacional Comunicação Cognição e Media (CICOM) (pp. 598610). Braga: Publicações da Faculdade de Filosofia da Universidade Católica Portuguesa.

Macedo, J. (2010). A Morte adiada. In Ladusãns, S. (eds.), Pessoas transparentes: questões actuais de bioética (pp. 195-208). Retirado de http://hdl. handle.net/1822/17145

Magalhães, O. E., Lopes, F. \& Costa-Pereira, A. (2017). Qual o papel do jornalismo na literacia da saúde? - estado da arte. In S. Pereira \& M. Pinto (Eds.), Literacia, Media e Cidadania - Livro de Atas do 4. ${ }^{\circ}$ Congresso (pp. 251-265). Braga: CECS.

Marcotte, P. \& Sauvageau, F. (2006). Les journalistes scientifiques: des éducateurs? Enquête auprès des membres de l'Association des communicateurs scientifiques du Québec. Les Cahiers du Journalisme, 15, 179-195. Retirado de https:// www.com.ulaval.ca/fileadmin/contenu/Cahiers Journalisme/PDF/15/11_Marcotte_Sauvageau.pdf

Martins, M. (2010). Prefácio: Jornalismo e sonho de comunidade. In M. Oliveira, Metajornalismo. Quando o jornalismo é sujeito do próprio discurso (pp. 9-13). Coimbra: Grácio Editor.

Marvin, C. \& Meyer, P. (2005). What kind of journalism does the public need? In G. Overholser \& K. Hall (Eds.), The press (pp. 400-411). Nova lorque: Oxford Universty Press.

Melki, J., Tamim, H., Hadid, D., Farhat, S., Makki, M., Ghandour, L. \& Hitti, E. (2020). Media Exposure and Health Behavior during Pandemics: The Mediating Effect of Perceived Knowledge and Fear on Compliance with COVID-19 Prevention Measures. Health Communication. https://doi.org/10.1080/10 410236.2020.1858564

Mora-Rodríguez, A. \& Melero-López, I. (2021). Seguimiento informative y percepción del riesgo 
ante la Covid-19 en España. Comunicar, 66, 71-81 https://doi.org/10.3916/C66-2021-06

Naidoo, J. \& Wills, J. (1998). Practising health promotion: dilemmas and challenges. Londres: Baillière Tindall.

Noar, S. \& Austin, L. (2020). (Mis)communicating about COVID-19: Insights from Health and Crisis Communication. Health Communication, 35(14), 1735-1739. https://doi.org/10.1080/10410236.2020.1 838093

Nutbeam, D. \& Lloyde, J. (2020). Understanding and Responding to Health Literacy as a Social Determinant of Health. Annual Review of Public Health, 42(3), 3.1-15. https://doi.org/10.1146/ annurev-publhealth-090419-102529

Organización Mundial de la Salud. (2006). Constitución de la Organización Mundial de la Salud. Retirado de: $\quad$ https://www.who.int/governance/eb/who_ constitution_sp.pdf?ua=1

Pavlik, J. (2001). Journalism and new media. Nova Iorque: Columbia University Press.

Raaum, O. (1986). Pressens tøyelige etikk. Journalisters yrkesmoral og selvjustis [The Elastic Ethics of the Press]. Oslo: Universitetsforlaget.

Raaum, O. (1999). Pressens tøyelige etikk. Journalisters yrkesmoral og selvjustis [The Elastic Ethics of the Press]. Oslo: Universitetsforlaget.

Ratzan, S. C. \& Parker, R. M. (2006) Health literacy - identification and response. Journal of Health Communication, 11(8), 713-715. https://doi. org/10.1080/10810730601031090

Ratzan, S. C. (2002). Public health at risk: media and political malpractice. Journal of Health communication, 7(2), 83-85. https://doi. org/10.1080/10810730290087969

Rodríguez-González, A. M. (2021). Educación para la salud, prevención y promoción comunitaria a través de la página de Facebook de un centro de salud de atención primaria. Revista Española de Comunicacion en Salud, 12(1), 58-66.

Sánchez-Duarte, J. M., \& Rosa, R. M. (2020). Infodemia y COVID-19. Evolución y viralización de informaciones falsas en España. Revista Española de Comunicacion en Salud, 12(1), 31-41.
Schmidt, L. (2008). Comunicar a ciência: o papel dos media e os problemas científico-ambientais. In $\mathrm{L}$. Schmidt \& J. P. Cabral (Eds.), Ciência e cidadania - homenagem a Bento de Jesus Caraça (pp. 85112). Lisboa: Imprensa de Ciências Sociais.

Schneider, S. \& Schimitt, C. J. (1998). O uso do método comparativo nas Ciências Sociais. Cadernos de Sociologia, 9, 49-87. Retirado de http://files. ibijus. webnode.com.br/200000915-4b6864c63f/ M\%C3\%A9todo\%20Explicativo\%20-\%20Texto\%202. pdf

Schwitzer, G. (2009). Seven words (and more) you shouldn't use in medical news. Retirado de http://www.healthnewsreview.org/toolkit/tips-forunderstanding-studies/7-words-and-more-youshouldnt-use-in-medical-news/

Schwitzer, G. (2010). The future of health journalism. Public Health Forum, 18(3), 19e1--19e3. https:// doi.org/10.1016/j.phf.2010.06.012

Sigal, L. (2008). Hand in hand for Korea: a peace process and denuclearization. Asian Perspective, 32(2), 5-19.

Sjøvaag, H. (2010). The reciprocity of journalism's social contract. Journalism Studies, 11(6), 874-888. https://doi.org/10.1080/14616701003644044

Spyridou, L., Matsiola, M., Veglis, A., Kalliris, G. \& Dimoulas, C. (2013). Journalism in a state of flux: Journalists as agents of technology innovation and emerging news practices. The International Communication Gazette, 75(1), 76-98. https://doi. org/10.1177/1748048512461763

Strömback, J. (2005). In search of a standard. Four models of democracy and their normative implications for journalism. Journalism Studies, 6(3), 331-345. https://doi.org/10.1080/14616700500131950

Tamez, L. E. V. (2020). Influencia de los medios de comunicación sobre la práctica médica defensiva: un abordaje cualitativo desde la perspectiva de médicos. Revista Española de Comunicacion en Salud, 11(2), 178-192.

Tanner, A. H., Friedman, D. B. \& Zheng, Y. (2015). Influences on the construction of health news: the reporting practices of local television news health journalists. Journal of Broadcasting \& Electronic Media, 59(2), 359-376. https://doi.org/10.1080/0883 $8151.2015 .1029123 \mathrm{~g}$ 
Teixeira, M. (2002). Uma visão do debate sobre as relações entre a ciência e o jornalismo. Pressupostos do Jornalismo de Ciência no Brasil, 133141. Retirado de http://www.casadaciencia.ufrj.br/ Publicacoes/terraincognita/cienciaepublico/artigos/ art10_pressupostos.pdf

Tejedor, S., Cervi, L., Tusa, F., Portales, M. \& Zabotina, M. (2020). Information on the COVID-19 pandemic in daily newspapers' front pages: case study of Spain and Italy. International Journal of Environmental Research and Public Health, 17(17), 1-16. http:// dx.doi.org/10.3390/ijerph17176330

Valero-Cedeño, N. J., Mina-Ortiz, J. B., Veliz-Castro, T. I., Merchán-Villafuerte, K. M., \& Perozo-Mena, A. J. (2020). COVID-19: La nueva pandemia con muchas lecciones y nuevos retos. Revisión Narrativa. Kasmera, 48(1). https://doi.org/10.5281/ zenodo.3745322

Viswanath, K., Lee, E. \& Pinnamaneni, R. (2020). We Need the Lens of Equity in COVID-19 Communication. Health Communication, 35(14), 1743-1746. https:// doi.org/10.1080/10410236.2020.1837445

Wang, P., Lu, W., Ko, N., Chen, Y., Li, D., Chang, Y. \& Yen, C. (2020). COVID-19-Related Information Sources and the Relationship with Confidence in People Coping with COVID-19: Facebook Survey Study in Taiwan. Journal of Medical Internet Research, 22(6), e20021. http://dx.doi.org/10.2196/20021

Wilson, A., Robertson, J., McElduff, P., Jones, A. \& Henry, D. (2010). Does it matter who writes medical news stories? PLoS Med, 7(9), e1000323. https://doi. org/10.1371/journal.pmed.1000323 